\title{
Effect of an Intervention to Improve Team Coordination on Patients Who are Likely to be Discharged on General Internal Medicine
}

Lina Pham, BA, Teri Arany, RN, William Coke, MD, Vivian Lo, MASc, Robert C. Wu, MD

\section{About the Authors}

Lina Pham is an analyst at the Centre for Innovation in Complex Care at the University Health Network in Toronto, Ontario; Teri Arany is a nurse manager at the University Health Network in Toronto; William Coke is the chief of medicine at Trillium Health Partners in Toronto, Ontario; Vivian Lo is a research coordinator at the University Health Network in Toronto; and Robert Wu is an assistant professor of medicine and site director of general internal medicine at Toronto General Hospital in Toronto, Ontario. Correspondence may be directed to robert.wu@uhn.on.ca.

\begin{abstract}
Summary
Effective discharge planning is important to ensuring a high quality of patient care and operational efficiency. The general internal medicine (GIM) environment is very complex and fluid, with multiple health professions providing care for patients. This makes coordination of discharges difficult, even with structured daily interprofessional rounds.

The purpose of this case-control study was to evaluate a discharge notification form that predicts nextday discharges. The main measures of the study, which took place in GIM wards at two academic teaching hospitals, were the completion and accuracy of the discharge forms, length of stay, discharge times, postdischarge admissions, and emergency department visits.

Seventy-six of 200 patients studied had information completed on the discharge notification form. The overall effect appeared to move discharges earlier in the day, while having no effect on length of stay. Patients whose information was completed on the discharge notification form were less likely to have an emergency department visit within 30 days post-discharge.

The use of a discharge notification form appears to move discharges earlier in the day, without increasing length of stay. Further refinement and evaluation is necessary to increase usage and assess the impact on outcomes of care.
\end{abstract}

\section{Résumé}

La planification des sorties efficace est très importante dans la prestation de soins de santé de grande qualité et dans l'efficience opérationnelle. L'environnement de médecine interne générale est très complexe, marqué par un flux constant d'activités et la participation de plusieurs disciplines de la santé à la prestation des soins. Dans un tel contexte, la coordination des sorties demeure difficile en dépit des tournées interprofessionnelles structurées quotidiennes.

L'objectif de l'étude cas témoins consistait à évaluer un formulaire d'avis de sortie qui indique les sorties du lendemain. Les principaux paramètres évalués dans le cadre de cette étude qui s'est déroulée aux unités de médecine interne générale de deux hôpitaux universitaires sont l'utilisation du formulaire et l'exactitude des renseignements qui y sont indiqués, la durée de l'hospitalisation, le moment des sorties, les admissions et les visites aux urgences après les sorties.

L'avis de sortie renfermait de l'information sur 76 des 200 patients étudiés. Prévoir les sorties plus tôt dans la journée semble être l'effet général de l'avis de sortie, qui n'a pas d'incidence par ailleurs sur la durée de l'hospitalisation. Les patients pour lesquels les renseignements paraissaient sur l'avis de sortie ont été moins enclins que les autres à se rendre aux urgences dans les 30 jours du congé.

L'utilisation d'un formulaire d'avis de sortie a pour effet, semble-t-il, de faire sortir les patients plus tôt dans la journée sans prolonger l'hospitalisation. Nous recommandons de peaufiner le formulaire et d'approfondir l'évaluation pour favoriser l'usage du formulaire et déterminer son impact sur les résultats des soins. 


\section{Introduction}

Effective discharge planning is critical to the efficiency of hospital operations. Unfortunately, hospitals continuously struggle with delayed discharges, resulting in overcrowded emergency departments. ${ }^{1,2}$ These operational inefficiencies create bottlenecks that affect the flow of incoming patients and decrease the quality of care patients receive. Often, the delays arise due to poor care coordination at the time of hospital discharge. In many cases, health care teams are not aware of the potential discharges and the barriers preventing discharge. ${ }^{3}$ Ultimately, this creates confusion, delays, and poor patient flow and care both in and out of the hospital. ${ }^{4}$ Health care providers and stakeholders recommend a standardized, policy-driven discharge protocol that can improve effective discharge planning. ${ }^{4}$

These issues are probably most inherent within services such as general internal medicine, where there is a high variability in diagnoses and a high amount of comorbidities seen among patients. ${ }^{5,6}$ The ability to discharge patients on a specific day is based on a series of events that are often difficult to predict, such as improvements in patient status or obtaining a procedure or investigation with reassuring results. The medical team is often the first to learn about changes in the discharge status of patients, but communication to the rest of the care team is often poor. ${ }^{3}$ Unfortunately, due to financial constraints, many hospitals are unable to have a coordinator or discharge planner to actively manage the process and coordinate care. ${ }^{7,8}$ A potential solution is to improve the communication regarding likely discharges. Our study objective was to evaluate and measure the effect of a tool in communicating likely discharges among the interprofessional teams.

\section{Methods}

Research Question: Does an intervention to improve the timely notification of potential discharges for the next day improve operational efficiency?

Design: A retrospective observational study of two general internal medicine sites-one with the intervention and one without (control).

Setting: The study was conducted at the Toronto Western Hospital (intervention) and Toronto General Hospital (control) on general internal medicine (GIM) wards. Each hospital is an academic teaching centre with four clinical teaching teams and a hospitalist team within their GIM divisions. The clinical teaching teams have an attending, a senior medical resident, junior medical residents, and medical students. The hospitalist teams are composed of one attending and two or three clinical fellows. Interprofessional ward rounds occur each weekday morning at both sites, and potential discharges are discussed at this time. The study was approved by the Research Ethics Board of the University Health Network.

Intervention: The tool—designed and developed by authors TA and WC-was iteratively refined at the Toronto Western Hospital and has been called the Patient Discharge Notification Form (PDNF) (Figure 1). The PDNF is a paper-based form

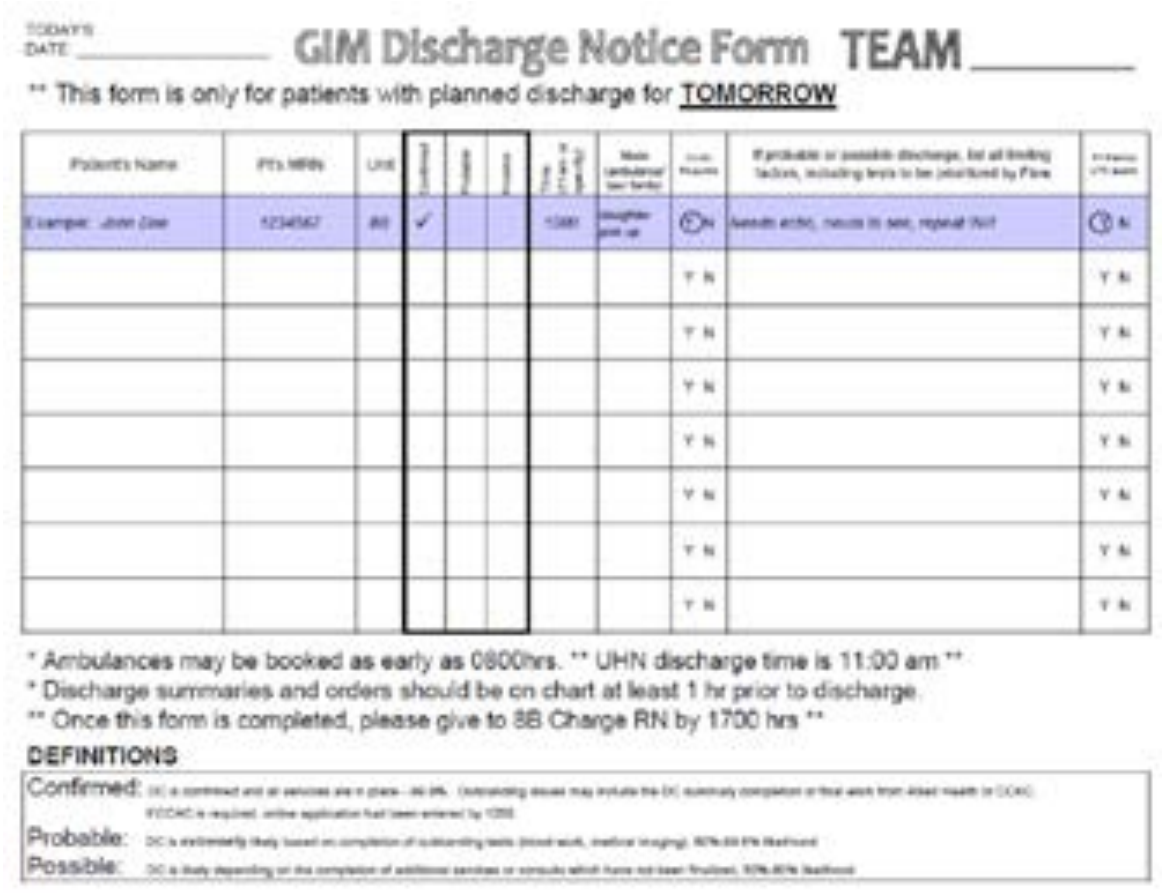

Figure 1. Patient Discharge Notification Form 
used for the purpose of triaging confirmed, probable, and possible discharges for upcoming patients. The physician completes the information on the form for each patient who was likely to be discharged. This information includes patient identifiers, likelihood of discharge, whether home services are required, and factors limiting the discharge. For patients whose discharges were not confirmed, the expectation was that the physician would enter the factors limiting discharge. Once complete, the information was collected and distributed to other clinicians, including nurse managers and patient flow coordinators. The purpose of the PDNF is to address barriers that may prohibit next-day discharge and to further facilitate ongoing discussion and action in ensuring effective, safe, and timely patient discharge. This tool was designed to overcome the gap in knowledge experienced by the medical care team about discharges for the next day. Although all patient discharges are discussed at care rounds in the morning, it was felt that having another point of communication later in the day would be beneficial, given the rapidly evolving nature of patient care. As well, the discharge form is meant to act as a checklist for physicians to make sure crucial pieces of the discharge are addressed, including informing the patient and family and arranging home services. The overall goal is that the PDNF would ultimately improve operational efficiency, reduce bed blocking, and reduce patient length of stay.

Data Collection: All patient discharge notification forms were collected. From both sites, 200 patients were randomly selected from all discharged GIM patients. These included patients who were discharged home or to another facility, patients who died, and patients who signed out against medical advice. All randomized patients from the Toronto Western Hospital were then screened from the collected PDNFs to see if there was any corresponding information on the patient.

Analysis: Descriptive statistics for the intervention site included 1) completion and accuracy rate of the PDNF, 2) discharge times for patients with PDNFs completed and those without PDNFs completed, 3) PDNF completion rate by different teams, and 4) PDNF completion rate for patients on GIM wards and those who were bed-spaced. Descriptive statistics included the following comparisons between the intervention site and the control site: average length of stay, average discharge time of day, and how PDNF completion affected patient readmission and emergency department visit averages at 30,60, and 90 days post-discharge. Chi-square tests were calculated for categorical variables.

\section{Results}

Patient admissions were randomly selected from October 1,
2012, to December 31, 2012. During this time, there were 813 discharges at Toronto Western Hospital and 1070 discharges at Toronto General Hospital.

\section{Completion and Accuracy of Information}

Of 200 patients discharged at the intervention site, information on $76(38 \%)$ patients on the associated PDNFs was available. Of the 76 patients with information listed, 26 PDNFs (34.2\%) were completed in full, while the rest had missing data, including 29 (38.2\%) who were missing estimated discharge time, $32(42.1 \%)$ who were missing discharge mode of transportation, and $20(26.3 \%)$ who were missing whether the patient or family was aware. In the section where a clinician would write any outstanding issues preventing the patient's discharge, $66.6 \%$ (30 of 45 possible or probable discharges) contained information. The outstanding issues could be categorized into areas relating to outstanding investigations $(22.2 \%)$, availability of home care services $(16.6 \%)$, availability of rehabilitation $(4.4 \%)$, and other items, such as family concerns, clinical status of the patient (i.e., improvement of delirium), and housing placement issues (24.4\%).

With respect to discharge times, patients who had their PDNF information completed were more likely to be discharged earlier (40.8\% before 1PM), compared to those who did not (33.0\% before 1PM) (Table 1). When patients were listed in the PDNF, the information was accurate in predicting discharges. For those listed as "confirmed" next-day discharges, 96.8\% were discharged the next day. For those listed as "probable" and "possible," $90 \%$ and $93.3 \%$ were discharged the next day, respectively (Table 2 ).

When the PDNF forms were broken down across the five different clinical teams, the completion rates ranged from $30 \%$ to $50 \%$. PDNFs were more likely to be completed for patients who were on the GIM ward, compared to off-service wards ( $43 \%$ vs. $32 \%$, respectively).

\section{Toronto Western Hospital vs. Toronto General Hospital}

The length of stay between both intervention and control hospital sites was the same, at 6.4 days for the 200 patients studied. In terms of actual discharge times, there was a considerable difference between both sites. Overall, the intervention site had earlier discharge times, most notably in the $1-3 \mathrm{PM}$ time bracket (13\% difference; $P=0.002$ ). (Table 1) There was no significant difference between patients at the intervention site and control site with respect to readmission or subsequent ED visits. There was also no difference in readmission between patients who had a completed PDNF and those who did not. However, there was a difference in 


\begin{tabular}{|c|c|c|c|c|c|}
\hline \multicolumn{6}{|c|}{ Intervention } \\
\hline $\begin{array}{c}\text { Discharge } \\
\text { Times }\end{array}$ & $\begin{array}{c}\text { PDNF } \\
(76)\end{array}$ & $\begin{array}{l}\text { No PDNF } \\
(124)\end{array}$ & $\begin{array}{l}\text { Total } \\
(200)\end{array}$ & Control (200) & $\begin{array}{l}\text { P value (control vs. } \\
\text { intervention) }\end{array}$ \\
\hline Before 11AM & $11(14.5 \%)$ & $21(16.9 \%)$ & $32(16.0 \%)$ & $23(11.5 \%)$ & 0.19 \\
\hline From 11 AM-1 PM & $20(26.3 \%)$ & $20(16.1 \%)$ & $40(20.0 \%)$ & $42(21.0 \%)$ & 0.43 \\
\hline From 1 PM -3 PM & $23(30.3 \%)$ & $33(26.6 \%)$ & $56(28.0 \%)$ & $30(15.0 \%)$ & 0.002 \\
\hline From $3 \mathrm{PM}-5 \mathrm{PM}$ & $11(14.5 \%)$ & $27(21.8 \%)$ & $38(19.0 \%)$ & $44(22.0 \%)$ & 0.46 \\
\hline From $5 \mathrm{PM}-12 \mathrm{AM}$ & $11(14.5 \%)$ & $23(18.6 \%)$ & $34(17.0 \%)$ & $61(30.5 \%)$ & 0.002 \\
\hline
\end{tabular}

Table 1. Discharge Time Between Intervention Site (with PDNF completed and without) and Control Site

\begin{tabular}{|c|c|c|c|}
\hline & $\begin{array}{c}\text { Confirmed: Actually } \\
\text { Discharged Next Day }\end{array}$ & $\begin{array}{c}\text { Probable: Actually } \\
\text { Discharged Next Day }\end{array}$ & $\begin{array}{c}\text { Possible: Discharged } \\
\text { Next Day }\end{array}$ \\
\hline Yes & $96.8 \%$ & $90 \%$ & $93.3 \%$ \\
\hline No & $3.2 \%$ & $10 \%$ & $6.7 \%$ \\
\hline Total: & 31 & 30 & 15 \\
\hline
\end{tabular}

Table 2. Toronto Western Hospital Types of Discharge Options and Likelihood of Successful Discharges (76 patients with a PDNF)

\begin{tabular}{|c|c|c|c|c|c|c|}
\hline & $\begin{array}{c}\text { Time } \\
\text { Intervals } \\
\text { (days) }\end{array}$ & $\begin{array}{c}\text { PDNF } \\
\text { Completed } \\
(n=76 \text { pts) }\end{array}$ & $\begin{array}{c}\text { PDNF Not } \\
\text { Completed } \\
(124 \text { pts) }\end{array}$ & $\begin{array}{c}\text { Intervention } \\
\text { Total }\end{array}$ & $\begin{array}{c}\text { Control } \\
(200 \text { pts) }\end{array}$ & $\begin{array}{c}\text { P value } \\
\text { (intervention } \\
\text { vs. control) }\end{array}$ \\
\hline Readmissions & 30 & $17(22.4 \%)$ & $27(21.8 \%)$ & $44(22 \%)$ & $35(17.5 \%)$ & \\
\hline & $31-60$ & $7(9.2 \%)$ & $11(8.9 \%)$ & $18(9 \%)$ & $25(12.5 \%)$ & \\
\hline & $61-90$ & $5(6.6 \%)$ & $9(7.3 \%)$ & $14(7 \%)$ & $8(4.0 \%)$ & \\
\hline Total & 90 & $22(28.9 \%)$ & $40(32.3 \%)$ & $62(31 \%)$ & $50(25 \%)$ & 0.18 \\
\hline ED visits & 30 & $7(9.2 \%)$ & $26(21.0 \%)$ & $33(16.5 \%)$ & $28(14.0 \%)$ & \\
\hline & $31-60$ & $3(3.9 \%)$ & $10(8.1 \%)$ & $13(6.5 \%)$ & $15(7.5 \%)$ & \\
\hline & $61-90$ & $3(3.9 \%)$ & $8(6.5 \%)$ & $11(5.5 \%)$ & $17(8.5 \%)$ & \\
\hline Total ED & 90 & $11(14.5 \%)$ & $32(25.8 \%)$ & $43(21.5 \%)$ & $44(22.0 \%)$ & 0.90 \\
\hline
\end{tabular}

Table 3. Readmission Averages Between Patients With PDNF Information Completed and Without at Intervention Site

the rate of ED visits within 30 days between those who had PDNF information completed and those who did not $(9.2 \%$ vs. $21.0 \% ; P=0.03$ ) (Table 3 ).

\section{Discussion}

We have presented an evaluation of an intervention to improve team coordination around patients who were likely to be discharged. For the $38 \%$ of patients who had information entered, the information was highly accurate in predicting discharges. The effect of the intervention appeared to shift the time of discharges to earlier in the day, compared to the site that did not have the intervention. Also, patients who had entered information were less likely to have an ED visit within 30 days post-discharge.

Although there are discharge planning tools described in the literature, they are typically aimed at transitional care planning for patients and do not describe effective communication among health care professionals around upcoming potential discharges. ${ }^{9}$ Most literature, toolkits, and resources emphasize the necessity of successful communication among health care teams but fail to provide a clear method on how to accomplish this. Most discharge literature focuses on either failed discharges due to insufficient communication between inpatient and outpatient settings, ineffective care transitions, or other patient-related issues. ${ }^{10}$ There is limited literature on the evaluation of specific discharge planning tools for interprofessional use in a hospital setting. Our communication tool provides a solid foundation in facilitating ongoing and daily discussions among health care teams to provide effective and meaningful discharge indicators that may prohibit a 
patient's pending discharge. Another alternative is for hospitals to hire dedicated discharge coordinators to organize and address potential barriers to discharges. Unfortunately, not all hospitals are equipped with the funding and resources for a dedicated discharge planner, despite the literature showing it improves quality in discharge planning. ${ }^{8}$ For hospitals that are financially constrained, the PDNF is a starting point. It is known that daily and structured interprofessional discussions on discharge-related issues improves communication and may reduce patient adverse events. ${ }^{11}$ Our tool was implemented in addition to structured daily rounds.

With only $38 \%$ of patients documented in the intervention, it appears the form has not been fully integrated into the routine clinical workflow. The low adoption rate might also be due to only being used on weekdays. Despite this, there have been some positive indicators to having the PDNF in place, such as discharges occurring earlier in the day, high accuracy of predicting next-day discharge, and facilitating a workflow needed to ensure next-day discharge. The impact of earlier discharges is important to our institution, as we are typically over census for budgeted beds for general medicine. Earlier discharges translate into shorter lengths of stay for patients in the emergency department who are admitted and waiting for a bed. By creating a standard process of communicating nextday discharges, it likely allowed the interprofessional team to ensure potential barriers to discharge were resolved earlier in the day.

We also saw significantly fewer emergency department visits in those who had PDNFs completed. This may relate to the fact that patients who had discharge forms completed were planned weekday discharges. Unplanned discharges, due to patients leaving against medical advice or weekend discharges, are known to increase the risk of return visits.

The major limitation of this study was that it retrospectively compared a site that implemented the intervention with one that did not. Many other factors could have caused the effects seen. As well, both sites are academic teaching centres and results may vary with non-academic centres. Further evaluation and refinement of this initial study are necessary.

Our future direction will be to improve the adoption rate. By incorporating a standard process seven days a week, we should be able to increase the number of patients documented using the tool. We also will reduce the work required by physicians by building an electronic tool that pre-populates demographic information. By moving to an electronic tool, we will be able to provide physicians with real-time feedback on adherence, accuracy, and completeness.

\section{Summary}

A notification system to improve coordination of care was accurate and might have moved discharges to occurring earlier in the day. This may translate to improved efficiency. Further refinement and study are necessary to improve the notification form and the adoption rate.

\section{Acknowledgements}

Funding from this research was provided by the Ontario Ministry of Health Alternate Funding Proposal Innovation Grant.

\section{References}

1. Manzano-Santaella A. From bed-blocking to delayed discharges: precursors and interpretations of a contested concept. Health Serv Manage Res 2010;23:121-7.

2. Majeed MU, Williams DT, Pollock R, et al. Delay in discharge and its impact on unnecessary hospital bed occupancy. BMC Health Serv Res 2012;12:410.

3. O'Leary KJ, Thompson JA, Landler MP, et al. Patterns of nurse-physician communication and agreement on the plan of care. Qual Saf Health Care 2010;19:195-9.

4. Wong E, Yam C, Cheung A, et al. Barriers to effective discharge planning: a qualitative study investigating the perspectives of frontline healthcare professionals. BMC Health Serv Res 2011;11:242.

5. Szecket N, Wong HJ, Wu RC, et al. Implementation of a continuous admission model reduces the length of stay of patients on an internal medicine clinical teaching unit. J Hosp Med 2012;7:55-9.

6. O'Leary KJ, Wayne DB, Haviley C, et al. Improving teamwork: impact of structured interdisciplinary rounds on a medical teaching unit. J Gen Intern Med 2010;25:826-32.

7. Houghton BA. Discharge planners and cost containment. Nurs Manage 1994;25:78-80.

8. Houghton A, Bowling A, Clarke KD, et al. Does a dedicated discharge coordinator improve the quality of hospital discharge? Qual Health Care 1996;5:89-96.

9. Balaban RB, Weissman JS, Samuel PA, et al. Redefining and redesigning hospital discharge to enhance patient care: a randomized controlled study. J Gen Intern Med 2008;23:1228-33.

10. Rennke S, Nguyen OK, Shoeb MH, et al. Hospital-initiated transitional care interventions as a patient safety strategy: a systematic review. Ann Intern Med 2013;158(5 Pt 2):433-40.

11. O'Leary KJ, Buck R, Fligiel HM, et al. Structured interdisciplinary rounds in a medical teaching unit: improving patient safety. Arch Intern Med 2011;171:678-84. 